\title{
Prevalence of Dysmenorrhea, Its Effect on Class Attendance and Treatment Pattern Among Medical, Nursing and Para-Medical Female Students of a University in Etawah District
}

\author{
Nilima Takhelchangbam' ${ }^{1}$, Tanya Agarwal ${ }^{2}$, Deepanshi Saxena ${ }^{3}$, Pooja Pathak ${ }^{4}$, Kanchan Soni $^{5}$, \\ Pankaj Kumar Jain ${ }^{6}$, Naresh Pal Singh $^{7}$ \\ 1,2,3,4,5 Post-graduate Student, ${ }^{6}$ Professor and Head, ${ }^{7}$ Professor, Department of Community Medicine, Uttar Pradesh University \\ of Medical Sciences, Saifai, Etawah, Uttar Pradesh, India.
}

DOI: https://doi.org/10.24321/2455.9199.202105

$\begin{array}{lllllll} & \mathbf{N} & \mathbf{F} & \mathbf{O}\end{array}$

\section{Corresponding Author:}

Nilima Takhelchangbam, Department of Community Medicine, Uttar Pradesh University of Medical Sciences, Saifai, Etawah, Uttar Pradesh, India.

E-mail Id:

nilimatakhel@gmail.com

Orcid Id:

https://orcid.org/0000-0003-2304-5933

How to cite this article:

Takhelchangbam N, Agarwal T, Saxena D, Pathak P, Soni K, Jain PK, Singh NP. Prevalence of Dysmenorrhea, Its Effect on Class Attendance and Treatment Pattern Among Medical, Nursing and Para-Medical Female Students of a University in Etawah District. Int J HealthCare Edu \& Med Inform. 2021;8(3):8-13.

Date of Submission: 2021-04-15

Date of Acceptance: 2021-09-15
$\begin{array}{lllllllllll}\mathbf{A} & \mathbf{B} & \mathbf{S} & \mathbf{T} & \mathbf{R} & \mathbf{A} & \mathbf{C} & \mathbf{T}\end{array}$

Background: Dysmenorrhea is defined as cramping pain in the lower abdomen occurring just before or during menstruation. Primary dysmenorrhea is responsible for significant loss of class/ work attendance. Many studies have also reported that self-medication is common among female students. Hence this study was undertaken to assess the scenario in medical, nursing, and paramedical female students.

Aims and Objectives: We conducted this study to determine the prevalence of dysmenorrhea and assess its associated symptoms, loss of class attendance, and the treatment pattern among female students pursuing medical, nursing, and paramedical courses.

Methods: We conducted a cross-sectional study on the female students pursuing medical, nursing, and paramedical courses at a university in Etawah district of Uttar Pradesh. A structured questionnaire was used to collect the data and analyzed using SPSS version 24 (IBM, Chicago, USA). Result: A total of 786 female students participated in the study. A high prevalence $(77 \%)$ of dysmenorrhea was reported. Of the students with dysmenorrhea, only 41 sought medical help while 269 self-medicated for the pain; the most consumed painkiller was found to be Mefenamic acid+ Dicyclomine HCL. The family history ( $X 2=17.2$, P-value $<0.001$ ) and academic performance ( $X 2=80.8$, P-value $<0.001$ ) were significantly associated with dysmenorrhea.

Conclusion: The findings of this research establish dysmenorrhea as a serious public health problem. It contributes to absenteeism and impairs everyday tasks, resulting in low academic achievement. Due to the widespread availability of over-the-counter medications, only few women seek medical counsel.

Keywords: Dysmenorrhea, Prevalence, Menstrual Pain, Painful Menstruation, Female Students 


\section{Introduction}

Dysmenorrhea is the most reported menstrual disorder. The American College of Obstetricians and Gynaecologists (ACOG) defines it as cramping pain in the lower abdomen associated with menstruation due to uterine contractions induced by the production of prostaglandins which is the etiology behind primary dysmenorrhea. ${ }^{1}$ Dysmenorrhea can be due to secondary causes such as endometriosis, uterine fibroids, adenomyosis, other disorders of the reproductive organs. While the pain tends to lessen after the first few days of a cycle in primary dysmenorrhea, it may continue even after the cycle ends in secondary dysmenorrhea. For many women, other symptoms such as nausea, vomiting, diarrhea, headache, and dizziness can accompany the pain. ${ }^{1}$

Worldwide, the reported prevalence of dysmenorrhea ranged from $15.8 \%$ to $89.5 \%$, with severe pain reported in $2 \%$ to $29 \%$ of menstruating individuals. ${ }^{2}$ The prevalence range reported in India is between $50 \%$ to $87.8 \%$. $^{3}$ Existing evidence suggests that the incidence and severity decrease with age and parity. ${ }^{4}$ Although higher rates are reported among adolescents, they can continue to persist until the late 20 s or later in life. Studies have shown that a range of risk factors have been attributed to dysmenorrhea with mixed results. It has been seen that lower age, smoking, higher Body Mass Index (BMI), early menarche, nulliparity, family history, longer and heavier menstrual flow, and stress are related to increased severity. On the other hand, education level, marital status, and sociodemographic status have shown inconclusive results. ${ }^{5}$

Dysmenorrhea can be a debilitating condition for many women, in turn impacting majorly on health-related quality of life, routine activities, and productivity. Apart from the clinical impacts, it is responsible for the considerable mental health issues and economic losses pertaining to increased medication, healthcare utilization, and loss of workdays. A study on adolescents reported $12 \%$ loss days of school/ work monthly due to dysmenorrhea, and $13 \%$ complained of inter-menstrual pain. They found a significant association between severe dysmenorrhea and absenteeism. ${ }^{6}$

The practice of self-medication is rampant among individuals who suffer from dysmenorrhea. The easy, unregulated, and widespread availability of over the counter drugs in the nation has contributed to women self-medicating for this disorder. It often leads to sub-therapeutic dosing, side effects, and toxicity. Diagnosis of serious causes can be delayed due to suppression of the pain with medications without proper medical advice or prescription. Other potential risks can be due to incorrect self-diagnosis, failure to seek appropriate medical advice, incorrect choice of medicine, failure to recognize and report adverse reactions, risk of dependence, drug interactions, among other risks. The practice of self-medication must be seen as an important public health issue and formulate steps to curb the problem.

We planned this study to determine the prevalence of dysmenorrhea among the female students pursuing medical, nursing, and paramedical courses and to assess the associated symptoms, academic loss, and treatment pattern for it among them.

\section{Materials and Methods}

\section{Study Setting}

The study was conducted at a medical university situated in the district Etawah of the state of Uttar Pradesh, India, that offers various courses, including medical, nursing, paramedical, among others.

\section{Study Design and Sampling}

This is a cross-sectional study conducted between August, 2019 to January, 2020. We adopted convenience sampling as approaching all the female students at all times was not feasible. At the end of two months of data collection, a total sample of 802 was obtained, of which 16 were excluded due to missing data or incorrectly filled questionnaires. The final sample size for analysis was 786, inclusive of medical, nursing, and paramedical female students. The process of enrolment is presented in a flowchart (Figure 1).

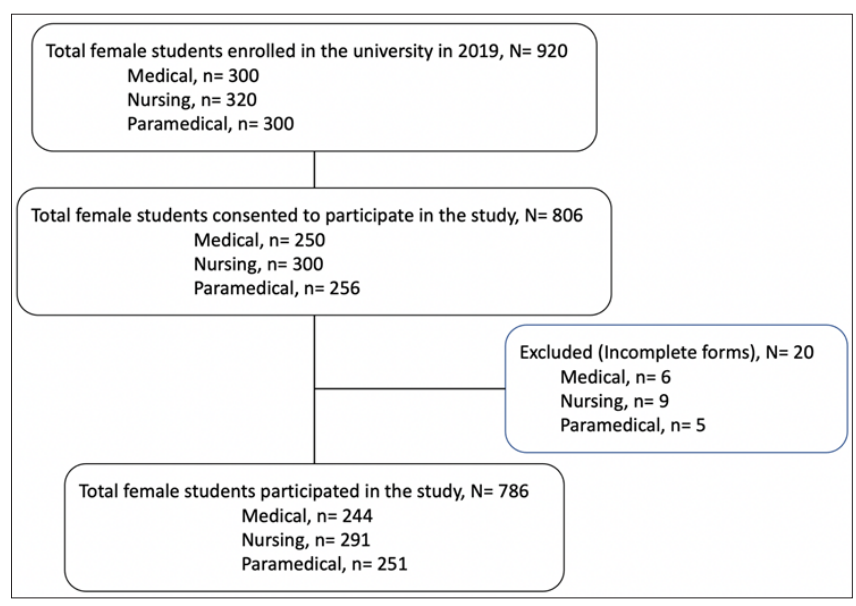

Figure I.Flowchart Depicting Study Participants Enrolment

\section{Procedure and Tool}

The data collected were self-reported. With permission obtained from the respective deans, the survey was conducted after a class period. The female students were requested to stay back for 30-45 minutes, and study objectives and procedures were explained in detail, including a tutorial on filling out the questionnaire by the principal investigator. Students not willing to participate were free to leave the class. Written informed consent was obtained from each willing student prior to questionnaire distribution. Supervised by a research assistant, structured 
questionnaires were distributed to be filled by all the female students present in the class. The validated questionnaire included four major sections. The first section enquired about the sociodemographic profile of the students. The second section collected data on their menstrual cycle and dysmenorrheal status with associated symptoms. The third section enquired about positive family history and pain management. The fourth section had questions pertaining to loss of attendance every month and the students' perception of academic loss due to dysmenorrhea.

If the student experiences lower abdominal, groin, lumbar pain a day before the start of the period and/or the first few days of the menstrual period, it was considered as primary dysmenorrhea. If they reported having symptoms consistent with dysmenorrhea along with a known secondary cause, the disorder was categorized as secondary dysmenorrhea. Regular cycles are usually at an interval of 20 to 40 days. The menstrual flow of more than seven days was considered a long cycle and is a risk factor for dysmenorrhea. ${ }^{1}$

\section{Ethical Approval}

Prior approval for conducting the study was obtained from the Institutional Ethics Committee before data collection. A written permission letter was also obtained from each of the deans of the three colleges of the University, viz. medical, nursing, and paramedical. Written informed consent was taken from each of the participants with the assurance that the participation is entirely voluntary and can withdraw from the study at will. They were also assured of data confidentiality.

\section{Statistical Analysis}

The data were entered, processed, and analyzed using the statistical package for social services SPSS version 24 (IBM, Chicago, USA). Descriptive analysis of categorical variables was conducted, and chi-square test was used to determine any association. Categorical variables are also presented in graphical representations. A P-value of $<0.05$ at a $95 \%$ confidence interval $(\mathrm{Cl})$ was considered statistically significant.

\section{Results}

Data collected from a total of 786 students were analyzed. The mean age was 20.9 years. The distribution of students in terms of course being studied was similar; 244 (31\%), 291 (37\%), and 251 (31.9\%) pursuing medical, nursing, and paramedical courses, respectively. Most of them were unmarried $(683,86.9 \%)$. A proportion of $41.5 \%$ belonged to the lower middle socio-economic class. Positive history of dysmenorrhea was given by 605 (77\%) students out of 786 Statistically significant associations were observed between dysmenorrhea and marital status, socioeconomic status, and duration of menstrual cycle (Table 1).

Among the study participants who reported dysmenorrhea $(n=605)$, the Mean \pm SD of the age of menarche was calculated to be $13.64 \pm 1.76$ years. Most of the total students had irregular menstrual cycles $(413,52.5 \%)$. The cycle interval was less than 28 days in 399 (50.8\%) of 786 students (Table 1). The majority of 258 (42.6\%) out of 605 students reported they had pain that lasted at least for two days during each cycle, with 194 (32.1\%) students experience pain for just one day and 24 (3.9\%) students reporting duration of pain for more than three days or persistence of pain throughout the cycle. Out of 605 students, 567 $(93.7 \%)$ of them believed they had primary dysmenorrhea, and $38(6.3 \%)$ of them were categorized into secondary dysmenorrhea based on the known gynecological cause reported in the questionnaire. Almost half (294, 48.6\%) of the students with dysmenorrhea reported they missed many classed due to period pain.

The most common symptom reported was lower back pain $(62 \%)$, followed by headache $(7.4 \%)$, vomiting $(5.0 \%)$, and diarrhea (4.0\%). Other symptoms such as leg pain, sleepiness, lightheadedness, blurring of vision, etc were reported by $12.6 \%$ of the students. About $8.3 \%$ of the students had no associated symptoms with the pain.

The students used different modalities to alleviate pain during episodes of dysmenorrhea. The majority of students $(310,51.2 \%)$ relied on pain killers, most commonly a combination of Mefenamic acid+ Dicyclomine HCL. A fraction of students $(110,18.2 \%)$ preferred hot pads or hot water bags, while seven students liked to use cold pads to relieve pain. Many students $(173,28.6 \%)$ reported that they did not use modalities to relieve pain and went about bearing the pain to avoid dependence (Figure 2). Of the students that took painkillers for pain relief, the majority $(269,86.8 \%)$ were on self-medication with over-the-counter drugs, and only 41 (13.2\%) students were taking prescription painkillers (Figure 3 ).

Out of the total students, 446 (56.7\%) reported a positive family history (dysmenorrhea in mother and siblings). We observe a statistically significant association of dysmenorrhea with positive family history (mother, siblings) $\left(\chi^{2}=17.2\right.$, P-value $\left.<0.001\right)$ with $447(56.9 \%)$ of 786 students reporting a positive family history (Table 2 ). Analysis of association between dysmenorrhea with loss of attendance showed a statistically significant result $\left(\chi^{2}=80.8\right.$, P-value $<0.001$ ) with 201 students who reported dysmenorrhea led to loss of attendance (Table 3). 
Table I.Sociodemographic Characteristics and Prevalence of Dysmenorrhea among the Study Participants

\begin{tabular}{|c|c|c|c|c|}
\hline \multirow{2}{*}{ Variable } & \multicolumn{2}{|c|}{ Dysmenorrhea } & \multirow{2}{*}{ Total (N/\%) } & \multirow{2}{*}{ P Value* } \\
\hline & Yes (n/\%) & No (n/\%) & & \\
\hline Age \pm SD (in years) & $21.04 \pm 2.5$ & $20.83 \pm 2.6$ & $21 \pm 2.56$ & 0.884 \\
\hline Age $\pm S D$ at menarche (in years) & $13.64 \pm 1.76$ & $13.51 \pm 1.75$ & $13.61 \pm 1.76$ & 0.876 \\
\hline \multicolumn{5}{|c|}{ Education } \\
\hline Medical & $184(23.4)$ & $60(7.6)$ & $244(31)$ & 0.468 \\
\hline Nursing & $231(29.4)$ & $60(7.6)$ & $291(37)$ & \\
\hline Paramedical & $190(24.2)$ & $61(7.8)$ & 251 (31.9) & \\
\hline \multicolumn{5}{|c|}{ Marital Status } \\
\hline Married & $53(6.7)$ & $50(6.4)$ & $103(13.1)$ & $<0.001$ \\
\hline Unmarried & $552(70.2)$ & $131(16.7)$ & $683(86.9)$ & \\
\hline \multicolumn{5}{|c|}{ Religion } \\
\hline Hindu & $484(61.6)$ & $145(18.4)$ & $629(80)$ & 0.863 \\
\hline Muslim & $104(13.2)$ & $32(4.1)$ & $136(17.3)$ & \\
\hline Christian & $12(1.5)$ & $2(0.3)$ & $14(1.8)$ & \\
\hline Others & $5(0.6)$ & $2(0.3)$ & $7(0.9)$ & \\
\hline \multicolumn{5}{|c|}{ Socioeconomic Status $^{\dagger}$} \\
\hline Upper (I) & $101(1.8)$ & $37(4.7)$ & $138(17.6)$ & 0.002 \\
\hline Upper middle (II) & $148(18.4)$ & $40(5.1)$ & $185(23.5)$ & \\
\hline Lower middle (III) & $269(34.2)$ & $57(7.3)$ & $326(41.5)$ & \\
\hline Upper lower (IV) & $55(7.0)$ & $27(3.4)$ & $82(10.4)$ & \\
\hline Lower (V) & $35(4.5)$ & $20(2.5)$ & $55(7.0)$ & \\
\hline \multicolumn{5}{|c|}{ Regularity of Menstrual Cycle } \\
\hline Regular & $280(35.6)$ & $93(11.8)$ & $373(47.5)$ & 0.228 \\
\hline Irregular & $325(41.3)$ & $88(11.2)$ & $413(52.5)$ & \\
\hline \multicolumn{5}{|c|}{ Menstrual Cycle Interval } \\
\hline$\geq 28$ days & $298(37.9)$ & $89(11.3)$ & $387(49.2)$ & 0.984 \\
\hline$<28$ days & $307(39.1)$ & $92(11.7)$ & $399(50.8)$ & \\
\hline \multicolumn{5}{|c|}{ Menstrual Cycle Duration } \\
\hline$\geq 7$ days & $286(36.4)$ & $106(13.5)$ & $392(49.9)$ & 0.008 \\
\hline$<7$ days & $319(40.6)$ & $75(9.5)$ & $394(50.1)$ & \\
\hline \multicolumn{5}{|c|}{$\begin{array}{c}{ }^{*} \text { Chi-square used. } \mathrm{P}<0.005 \text { significant } \\
{ }^{+} \text {Modified BG Prasad Scale }\end{array}$} \\
\hline
\end{tabular}

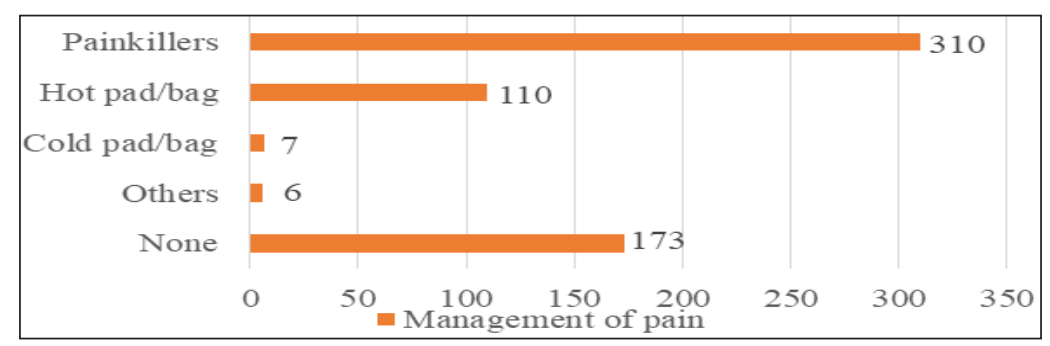

Figure 2. Management Pattern of Dysmenorrheal Pain at Home 


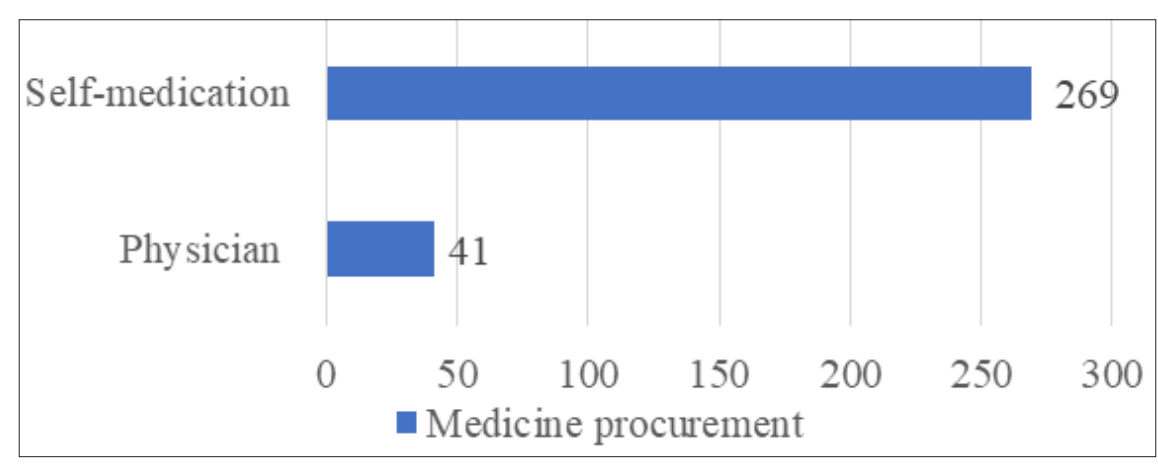

Figure 3.Prevalence of Self-medication among Students with Dysmenorrhea

Table 2.Association of Family History with Personal History of Dysmenorrhea

\begin{tabular}{|c|c|c|c|c|}
\hline \multirow{2}{*}{ Painful cycles } & \multicolumn{2}{|c|}{ Positive family history $\mathbf{n}(\%)$} & \multirow{2}{*}{ Total $\mathbf{n}$ (\%) } & \multirow{2}{*}{ Chi square } \\
\cline { 2 - 3 } & Yes & No & 605(100) & \multirow{2}{*}{$\chi^{2}=17.2$} \\
Yes & $369(61.0)$ & $236(39.0)$ & $181(100)$ & \begin{tabular}{c} 
p value $<0.001$ \\
\hline No
\end{tabular} \\
\hline Total & $78(43.1)$ & $103(56.9)$ & $786(100)$ & \\
\hline
\end{tabular}

Table 3. Association of Loss of Attendance with Personal History of Dysmenorrhea

\begin{tabular}{|c|c|c|c|c|}
\hline \multirow{2}{*}{ Painful cycles } & \multicolumn{2}{|c|}{ Loss of attendance $\mathbf{n}(\%)$} & \multirow{2}{*}{ Total $\mathbf{n}(\%)$} & \multirow{2}{*}{ Chi square } \\
\cline { 2 - 3 } & Yes & No & $605(100)$ & \multirow{2}{*}{$\begin{array}{c}\chi^{2}=80.8 \\
\text { p value }<0.001\end{array}$} \\
\hline Yes & $201(33.2)$ & $404(66.8)$ & $181(100)$ & $786(100)$ \\
\hline Total & $0(0.0)$ & $181(100)$ & $585(74.4)$ & \\
\hline
\end{tabular}

\section{Discussion}

Dysmenorrhea is the most reported gynecological disorder among adolescents and young female adults. The taboo around menstruation and the impact of dysmenorrhea on the physical and mental health of these young individuals hamper routine activities, loss of school/workdays, and inadequate and improper treatment adoption. The prevalence of dysmenorrhea in India is reported to be between the range of 50 to $87.8 \%{ }^{7-9}$ Our study found a similar finding, with a majority of the students reporting dysmenorrhea. We found a prevalence of $77 \%$ in our study. Similar prevalence was reported by Alaettin Unsal et al. ${ }^{10} \mathrm{Higher}$ prevalence among young female adults have been reported by Fatima et ( $84 \%$ ) and by Mool Raj et al. (84.2\%). ${ }^{11,12}$ The mean age for menarche among students with dysmenorrhea ( $n=605$ ) was found to be $12.2 \pm 1.2$ years. A similar mean age of $12.56 \pm 0.94$ has been reported by Fatima et (2015). ${ }^{11}$ Majority, 86.9\%, were unmarried. Most of the students who reported dysmenorrhea had regular menstrual cycles $(491,81 \%)$, with 342 students having cycle intervals of less than 28 days and $96.5 \%$ of 605 students had cycle duration of less than seven days.

Primary dysmenorrhea was reported by 567 students, and
38 of them were aware of their gynecological disorders that were the cause of dysmenorrhea. This indicates that only a small fraction of students were aware of their diagnosis of secondary dysmenorrhea, while the majority assumed they had primary disorder without having undertaken any medical evaluations. In this study, almost half of the students with dysmenorrhea (43\%) experience days of pain for more than two days, sometimes lasting for more than three days and, in few, throughout the cycle.

The most consumed painkiller was found to be a combination of Mefenamic Acid and Dicyclomine HCL, which is available over the counter. Half of the students with dysmenorrhea rely on painkillers to alleviate pain, of which only 41 students were taking prescription painkillers. This indicates that there is over-reliance on self-medication that can lead to serious risks, including delay of proper diagnosis, incorrect or inadequate dosing of medication, side effects and toxicity, and delay in seeking medical care in case of emergencies. The other self-treatment modalities adopted by the students were the use of hot or cold-water pads/ bags, ayurvedic preparations, and others. There has been much evidence of an epidemiological link between family history and dysmenorrhea. One of the studies reported a significant association of positive history of dysmenorrhea 
with primary dysmenorrhea $(\mathrm{AOR}=5.19,95 \% \mathrm{CL}$; 3.12, 8.37). ${ }^{9}$ We also found that there is a strong association between positive family history and dysmenorrhea $\left(\chi^{2}=\right.$ 17.2, P-value <0.001).

In our study, almost half of the students (48.6\%) with dysmenorrhea reported a loss of attendance every month due to the symptoms of dysmenorrhea. The more alarming finding we observed was the reported hampering of academic performance due to dysmenorrhea by the students who suffer from dysmenorrhea. The association was highly statistically significant between dysmenorrhea and hampering of academic performance $\left(\chi^{2}=80.8, P\right.$-value $<0.001)$. A study by Esra Bilir et al. found that $56 \%$ of the students had lower academic performance attributed to dysmenorrhea.

\section{Conclusion}

Dysmenorrhea is a common ailment among young women with a consistently high prevalence worldwide and countrywide alike. As a result, a large percentage of women often miss school or University, or workdays as well as impact their academic performance on top of the pain and discomfort dysmenorrhea renders. Given the importance of these social and academic limitations associated with dysmenorrhea in terms of public health, school or University administrations can play a critical role in reducing the prevalence of dysmenorrhea by spreading awareness, providing health check-ups, and encouraging appropriate treatment-seeking behaviours.

\section{Source of Funding: Self-Financed \\ Conflic of Interest: None \\ References}

1. The American College of Obstetricians and Gynecologists [Internet]. Dysmenorrhea: Painful Periods - ACOG [cited 2021 Jan 30]. Available from: https://www. acog.org/Patients/FAQs/Dysmenorrhea-PainfulPeriods?IsMobileSet=false.

2. Calls KA. Dysmenorrhea [cited 2021 July 28]. Available from: https://emedicine.medscape.com/ article/253812-overview.

3. Omidvar S, Bakouei F, Amiri FN, Begum K. Primary ysmenorrhea and menstrual symptoms in Indian female students: Prevalence, Impact and Management. Glob J Health Sci. 2016;8(8):53632. doi:10.5539/gjhs. v8n8p135. [Pubmed] [Google Scholar]

4. Payne LA, Rapkin AJ, Seidman LC, Zeltzer LK, Tsao $\mathrm{JCl}$. Experimental and procedural pain responses in primary dysmenorrhea: A systematic review. J Pain Res. 2017;10:2233-2246. doi:10.2147/JPR.S143512. [Pubmed] [Google Scholar]

5. Ju H, Jones $\mathrm{M}$, Mishra $\mathrm{G}$. The prevalence and risk factors of dysmenorrhea. Epidemiol Rev. 2014;36(1):104-
113. doi:10.1093/epirev/mxt009. [Pubmed] [Google Scholar]

6. Zannoni L, Giorgi M, Spagnolo E, Montanari G, Villa G, Seracchioli R. Dysmenorrhea, absenteeism from school, and symptoms suspicious for endometriosis in adolescents. J Pediatr Adolesc Gynecol. 2014;27(5):258265. doi:10.1016/J.JPAG.2013.11.008. [Pubmed] [Google Scholar]

7. Agarwal AK, Agarwal A. A study of dysmenorrhea during menstruation in adolescent girls. Indian J Community Med. 2010;35(1):159-164. doi:10.4103/09700218.62586. [Pubmed] [Google Scholar]

8. Singh A, Kiran D, Singh H, Nel B, Singh P, Tiwari P. Prevalence and severity of dysmenorrhea: a problem related to menstruation, among first and second year female medical students. Indian J Physiol Pharmacol. 2008;52(4):389-397. [Google Scholar]

9. Azagew AW, Kassie DG, Walle TA. Prevalence of primary dysmenorrhea, its intensity, impact and associated factors among female students' at Gondar town preparatory school, Northwest Ethiopia. BMC Womens Health. 2020;20(1):1-7. doi:10.1186/s12905-019-08734. [Google Scholar]

10. Unsal A, Ayranci U, Tozun M, Arslan G, Calik E. Prevalence of dysmenorrhea and its effect on quality of life among a group of female university students. Ups J Med Sci. 2010;115(2):138-145. doi:10.3109/03009730903457218. [Pubmed] [Google Scholar]

11. Fatima A, Mamatha KR, Ambika B, Rajarathna K. Self-medication practice in primary dysmenorrhea among medical and paramedical students - a crosssectional questionnaire study. Natl J Physiol Pharm Pharmacol. 2017;7(5):458-463. doi:10.5455/ njppp.2017.7.1233424122016. [Pubmed] [Google Scholar]

12. Kural M, Noor NN, Pandit D, Joshi T, Anjali P. Menstrual characteristics and prevalence of dysmenorrhea in college going girls. J Fam Med Prim care. 2015;4(3):426431. [Pubmed] [Google Scholar] 